\title{
Initial organization of the Drosophila dorsoventral axis depends on an RNA-binding protein encoded by the squid gene
}

\author{
Richard L. Kelley ${ }^{1}$ \\ Department of Zoology, University of Texas at Austin, Austin, Texas 78712 USA
}

Females mutant for the newly identified squid (sqd) gene are sterile and lay eggs that display only dorsal structures. The resulting embryos are also dorsalized even if fertilized by wild-type sperm. The gene acts midway through oogenesis at about the time dorsoventral $(D / V)$ axis is established within the growing egg chamber. The sqd gene encodes at least three distinct proteins generated by alternative RNA processing that are members of a well-characterized family of RNA-binding proteins. At least one Sqd isoform is essential in somatic tissues. The ventralizing mutations gurken (grk), torpedo (tor), and cornichon are all epistatic to sqd. Strong alleles of grk and top can act as dominant suppressors of sqd dorsalization. A model of D/V axis formation is presented postulating that squid is needed to organize a concentration gradient of a morphogen originating in the germinal vesicle.

[Key Words: Dorsoventral axis; Drosophila; hnRNP; oogenesis]

Received February 4, 1993; revised version accepted March 16, 1993.

One of the best understood model systems for early pattern formation is the dorsoventral $(\mathrm{D} / \mathrm{V})$ axis in Drosophila embryos (for review, see Anderson 1989; Levine and Harding 1989; Govind and Steward 1991). A complex biochemical cascade of maternally supplied proteins culminates with differential transcription of the zygotic genome along the $\mathrm{D} / \mathrm{V}$ axis. This requires partitioning the dorsal (dl) transcription factor between inactive cytoplasmic and active nuclear locations (Steward 1987, 1989; Doyle et al. 1989; Roth et al. 1989; Rushlow et al. 1989; Ray et al. 1991). This subcellular distribution of $\mathrm{Dl}$ protein is determined by extraembryonic spatial cues received by the transmembrane Toll (Tl) receptor in the early embryo (Hashimoto et al. 1988, 1991). These cues may be deposited in the vitelline membrane much earlier during oogenesis and act as a stable template on which the embryo organizes its body plan (Stein et al. 1991; Stein and Nüsslein-Volhard 1992).

Although these late events are well characterized, little is known about the mechanism by which eggs initially generate $\mathrm{D} / \mathrm{V}$ asymmetries during oogenesis. Drosophila eggs develop within structures called egg chambers composed of three cell types (Mahowald and Kambysellis 1980). In addition to the oocyte, there are 15 interconnected nurse cells that supply most of the maternally inherited nonyolk cytoplasm to the egg. These

${ }^{1}$ Present Address: Department of Cell Biology, Baylor College of Medicine, Texas Medical Center, Houston, Texas 77030 USA. germ cells are surrounded by a monolayer of $\sim 1000$ follicle cells that secrete the vitelline membrane and chorion onto the surface of the oocyte. If subsets of follicle cells insert spatial cues into the vitelline membrane as it is being made, then how are they polarized along the $\mathrm{D} / \mathrm{V}$ axis by mid-oogenesis? Manseau and Schüpbach (1989) have postulated that follicle cells are told their location by a dorsalizing morphogen released by the underlying germ cells. This morphogen is probably delivered to the surface of the oocyte and induces the surrounding follicle cells to adopt appropriate $\mathrm{D} / \mathrm{V}$ fates depending on the amount of the morphogen that they receive. Follicle cells receiving high doses of this morphogen acquire a dorsal fate, and those receiving little or none enter a ventral fate by default.

This model is based on mutations that produce egg shells and embryos with abnormal D/V axes. Eggs laid by females homozygous for torpedo (top), gurken (grk), or cornichon (cni) are ventralized and have reduced dorsal structures (Schüpbach 1987; Ashburner et al. 1990). These mutants are thought to be defective in the signaling pathway between the oocyte and follicle cells so that no follicle cell is able to acquire a dorsal fate. The opposite phenotype is observed in eggs and embryos derived from mothers mutant for $f_{s}(1) K 10$ (K10), spire (spir), or cappuccino (capu) (Wieschaus et al. 1978; Manseau and Schüpbach 1989). These eggs are dorsalized and deficient in ventral structures. One possible interpretation of this phenotype is that too many follicle cells receive the dor- 
salizing signal. Here, I report the discovery of a new dorsalizing mutant in this early class. The phenotypic and molecular characterization of squid (sqd) presented here supports the Manseau and Schüpbach (1989) model and demonstrates that an RNA-binding protein plays a central role in establishing egg polarity.

\section{Results}

\section{Isolation of sqd mutations}

I isolated the initial $s q d^{1}$ mutation in a large screen of female sterile insertional mutants using a single rosy ${ }^{+}$ $\left(r y^{+}\right)$-marked $\mathbf{P}$ element, and additional alleles are shown in Table 1A. Homozygous $s q d^{1}$ females lay grossly abnormal eggs, but the males are fertile. The $r y^{+}$ marked $P$ element was remobilized by supplying $P$ transposase (Robertson et al. 1988) to generate imprecise excisions as well as partial and full revertants. These new mutations could be arranged in a continuous phenotypic series from fertile with only minor chorion polarity defects to zygotic lethal alleles.
Wild-type eggs have two prominent respiratory appendages emerging near the dorsal midline at the anterior end of the egg (see Fig. 1A). The eggs produced by hemizygous females carrying the weak hypomorphic allele, $s q d^{p \times 3} / D f$, display variable morphology, with many eggs having two enlarged respiratory appendages located on the sides rather than flanking the dorsal midline (see Fig. 1D|. A chemically induced allele, $s q d^{K 12}$, displays a similar weak phenotype (see Fig. 1B ). This is interpreted as an expansion of dorsal chorion at the expense of ventral structures. All of the eggs laid by females carrying the original $s q d^{1}$ allele are small with a ring of filaments or a cylinder of chorionic material encircling the anterior end of the egg (see Fig. 1C). This structure is a grossly expanded respiratory appendage. I conclude from this morphology that eggs from sqd mothers are dorsalized and the degree of dorsalization varies with the severity of the allele examined. Eggs of $s q d$ mothers resemble those produced by $f_{s}(1) K 10$ females, although strong sqd alleles produce a more extreme dorsalized phenotype than null K10 alleles (Wieschaus et al. 1978). Both capu and spir females also produce some partially dorsalized eggs

Table 1. Mutations used in this study

\begin{tabular}{|c|c|c|c|c|c|c|c|}
\hline \multicolumn{8}{|c|}{ A. Mutant phenotypes } \\
\hline 1 & \multicolumn{3}{|c|}{$r y^{+} \mathrm{P}$ element } & D1 & Dl & Dl & this work \\
\hline LZ48 & \multicolumn{3}{|c|}{ lacZ $\mathrm{P}$ element } & D1 & D1 & D1 & A. Spradling \\
\hline AN240 & \multicolumn{3}{|c|}{ lacZ P element } & D1 & D1 & D1 & T. Schüpbach \\
\hline $\mathrm{K} 12$ & \multicolumn{3}{|c|}{ EMS } & + & D2 & D4 & T. Schüpbach \\
\hline px3 & \multicolumn{3}{|c|}{ imprecise excision } & + & D3 & D4 & this work \\
\hline ix43 & \multicolumn{3}{|c|}{ internal deletion of $r y$, imprecise excision } & D1 & D1 & D1 & this work \\
\hline ix 50 & \multicolumn{3}{|c|}{$\sim 2-\mathrm{kb}$ deletion imprecise excision } & lethal & lethal & D1 & this work \\
\hline ix 77 & \multicolumn{3}{|c|}{$\sim 200$-bp deletion imprecise excision } & lethal & semilethal & D1 & this work \\
\hline r5 & \multicolumn{3}{|c|}{ precise excision } & + & + & + & this work \\
\hline Stock & \multicolumn{3}{|c|}{ Cytology } & Referenc & & & \\
\hline Df(3R) redP52 & \multirow{5}{*}{\multicolumn{2}{|c|}{$\begin{array}{l}88 \mathrm{~A} 4 ; 88 \mathrm{~B} 1,2 \\
87 \mathrm{E} 2 ; 88 \mathrm{~A} 6-10 \\
87 \mathrm{~F} 1 ; 87 \mathrm{~F} 15 \\
87 \mathrm{D} 14-\mathrm{E} 1 ; 87 \mathrm{~F} 11-12 \\
87 \mathrm{~B} 12-15 ; 87 \mathrm{E} 8-11\end{array}$}} & & & & & \\
\hline $\begin{array}{l}\mathrm{DH}(3 \mathrm{BR}) \mathrm{red}^{\mathrm{ruc}} \\
\mathrm{Df}(3 \mathrm{R}) 293^{\gamma 5}\end{array}$ & & & $\begin{array}{l}\text { wild type } \\
\text { mutant }\end{array}$ & Lindsley & mm (1992) & & \\
\hline $\begin{array}{l}\mathrm{DH}(3 \mathrm{~K}) \\
\mathrm{Df}(3 \mathrm{R}) \text { urd }\end{array}$ & & & mutant & Lindsley & $\mathrm{mm}(1992)$ & & \\
\hline $\mathrm{Df}(3 \mathrm{R}) 126 \mathrm{c}$ & & & mutant & Lindsley & $\mathrm{mm}(1992)$ & & \\
\hline $\operatorname{Df}(3 \mathrm{R}) r y^{615}$ & & & wild type & Lindsley & $\mathrm{mm}(1992)$ & & \\
\hline \multirow[b]{2}{*}{ Gene, markers } & \multirow{2}{*}{\multicolumn{4}{|c|}{$\begin{array}{l}\text { C. Other dorsoventral mutations used in this work } \\
\text { Phenotype }\end{array}$}} & & & \\
\hline & & & & & Source & & \\
\hline \multicolumn{2}{|l|}{$f_{s}(1) \mathrm{K} 10 \mathrm{wf}$} & \multicolumn{2}{|c|}{ dorsalizing } & & T. Schüpbach & & \\
\hline \multirow{2}{*}{\multicolumn{2}{|c|}{$\begin{array}{l}g r k^{H K} \text { cn bw } \\
g r k^{w g} \text { cn bw }\end{array}$}} & \multicolumn{2}{|c|}{ ventralizing } & & T. Schüpbach & & \\
\hline & & \multirow{2}{*}{\multicolumn{2}{|c|}{ ventralizing }} & & T. Schüpbach & & \\
\hline \multicolumn{2}{|l|}{ top $p^{1}$ pr $b$ bw } & & & ventralizing hypomorphic point mutation & T. Schüpbach & & \\
\hline \multirow{2}{*}{\multicolumn{2}{|c|}{$\begin{array}{l}\text { Df C18A, b pr cr } \\
\text { cniAA112 b pr cn }\end{array}$}} & \multicolumn{2}{|c|}{ small deletion of top } & & T. Schüpbach & & \\
\hline & & ventralizin & & & T. Schüpbach & & \\
\hline
\end{tabular}

(A) sqd alleles: The phenotype of each allele was assayed as homozygotes $(\mathrm{X} / \mathrm{X})$, in combination with $D f$ urd (X/Df), and in combination with $s q d^{1}\left(\mathrm{X} / s q d^{1}\right)$. The severity of the dorsalized sqd phenotype was scored by the following criteria: (D4) Fertile; mostly wild-type egg morphology; 1-10\% partially dorsalized eggs with enlarged respiratory appendages located laterally as in Fig. 1B. (D3) Semisterile; most eggs partially dorsalized as shown in Fig. 1B, although some wild-type eggs and progeny are also produced. (D2) Sterile; all eggs partially dorsalized. (D1) Sterile; all eggs strongly dorsalized as shown in Fig. $1 C_{\text {; }}$ rarely, if ever, fertilized. $|+|$ Wild type.

$(B)$ The deletions used to map the sqd mutation and their cytological locations.

$(C)$ The ventralizing mutations used to test epistatic interactions. 


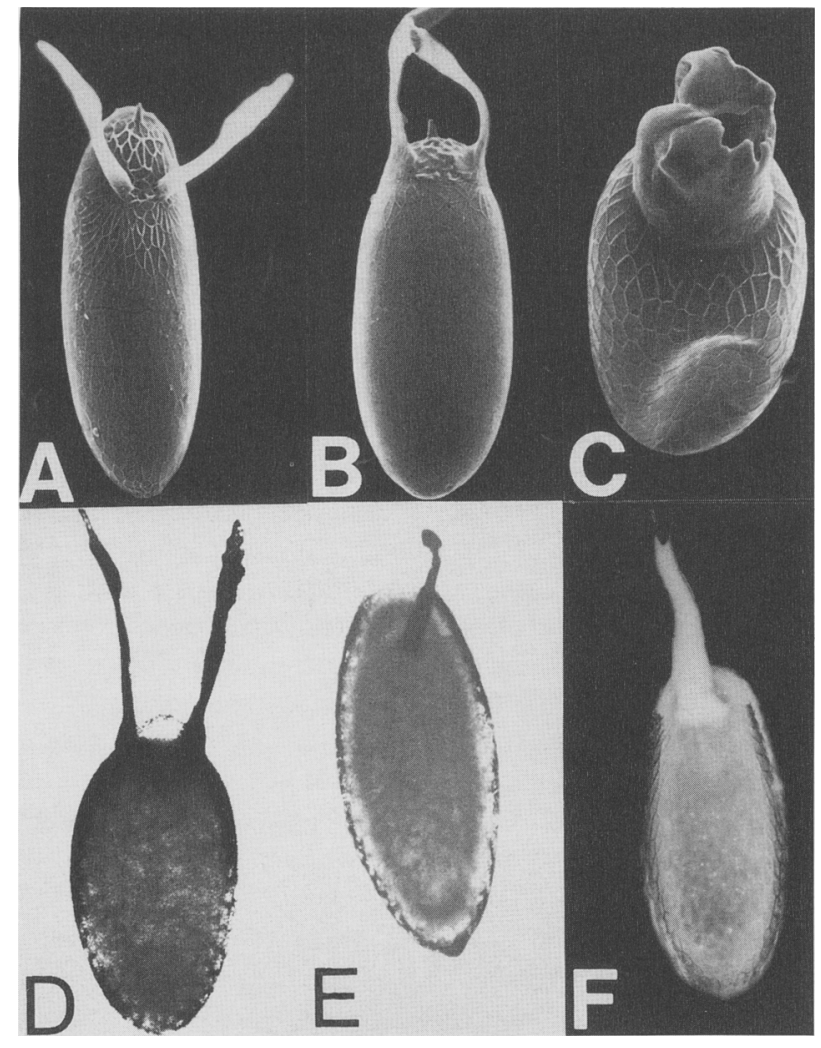

Figure 1. Egg morphology in wild-type and sqd mutants. $(A-C)$ Scanning electron microscope; $(D, E)$ bright field; $(F)$ dark field. (A) Wild-type egg showing the two respiratory appendages located on either side of the dorsal midline. Dorsal view; anterior is up. (B) Weakly dorsalized egg from $s q d^{K 12} / D$ f urd mother. $(C)$ Strongly dorsalized egg from $s q d^{1}$ mother. $(D)$ Weakly dorsalized egg from $s q d^{p \times 3} / D f$ urd mother. $(E)$ Ventralized egg from top $1 / D f c 18$; $s q d^{i x 43} / s q d^{i x 28}$ mother. $(F)$ Weakly ventralized egg from $D f c 18 /+$; $s q d^{i \times 43} / s q d^{i \times 28}$ mother.

(Manseau and Schüpbach 1989), but sqd is much more extreme and fully penetrant.

The reduced size of the egg is the result of incomplete transfer of cytoplasm from the nurse cells to the oocyte at the end of oogenesis (Fig. 2B,C). Although this phenotype superficially resembles that of kelch and chickadee mutants (Schüpbach and Wieschaus 1991; Cooley et al. 1992), sqd activity is not necessary for nurse cell cytoplasm transfer (see below). The small size appears to be a secondary result of aberrant centripetal migration of anterior follicle cells blocking transfer of nurse cell cytoplasm. In addition, too few follicle cells are left to construct the main body of the chorion because more are recruited to make respiratory appendages.

The different P-element insertional alleles display the same dorsalized phenotype as either hemizygotes or homozygotes, indicating that the $\mathrm{P}$ elements cause strong loss-of-function mutations (see Table 1A). Weak alleles such as px3 or K12 are unusual, in that homozygous females are fertile and have normal egg morphology. However, when trans to a deletion of sqd, most or all of their eggs are partially dorsalized (see Fig. 1B,D). Although the sqd product appears to be in excess in wildtype egg chambers, large differences in phenotype can be produced by twofold changes in sqd activity when the level is lowered in mutants. Females heterozygous for the weak $p \times 3$ excision allele and the original $s q d^{1} \mathrm{P}$ in sertion are fertile, and only $\sim 5 \%$ of the eggs are partially dorsalized (see Table 1A). The finding that $s q d^{1}$ and a $s q d$ deletion interact differently with the weak alleles shows that the P-insertion alleles are not complete nulls.

Some of the imprecise excisions recovered were found to have small deletions flanking the original P-insertion site. The lethal ix50 allele removes the first coding sqd exon and may affect the adjacent gene. The ix 77 allele lacks $\sim 200-300$ bp of DNA in the $5^{\prime}$-untranslated leader of the sqd gene (see Fig. 5A, below) and is semilethal in combination with a sqd deletion (see Table 1A). This

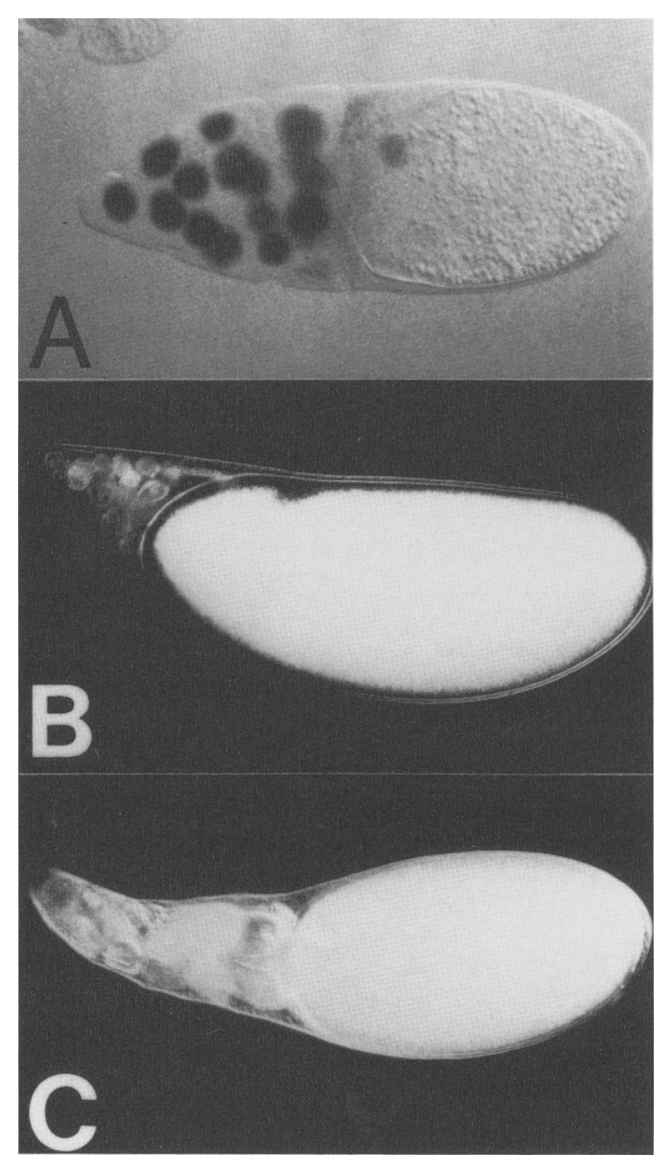

Figure 2. (A) A stage-10 egg chamber from a homozygous $s q d^{L Z 48}$ mother that carries a lacZ enhancer trap inserted in the first $s q d$ exon stained with X-gal. The 15 polyploid nurse cells (left) stain intensely and the germinal vesicle (center) less so. The germinal vesicle has migrated the dorsal side of the oocyte. (B) A stage-13 wild-type egg chamber showing that only the degenerating nurse cell nuclei remain outside the oocyte. (C) A stage-13 egg chamber from a $s q d^{1}$ female showing that a portion of the nurse cell cytoplasm failed to move into the oocyte and remains trapped within the cylinder of expanded respiratory appendage. 
demonstrates that $s q d$ plays an essential function in a nonovarian tissue. The original transposon insertional alleles are only deficient for an ovarian $s q d$ function needed during $\mathrm{D} / \mathrm{V}$ axis formation but retain the essential somatic activity. Most animals with lethal sqd mutations die as second- or third-instar larvae, but a few pupate. They do not display any obvious pattern defects but are smaller and much weaker than their $s q d^{+}$siblings. The rare adult ix 77 escapers lay tiny eggs that are strongly dorsalized (data not shown).

\section{sqd follicle cells have altered $D / V$ fate}

Egg chambers were examined for morphological defects. The earliest sign of $\mathrm{D} / \mathrm{V}$ axis formation is the migration of the germinal vesicle to the presumptive dorsal side of the oocyte by stage 9 . This migration is not altered in $s q d$ egg chambers (see Fig. 2A), suggesting that sqd acts later. $\mathrm{D} / \mathrm{V}$ axis is determined before stage 10 (Montell et al. 1991), and the follicle cells in sqd egg chambers display a dorsalized morphology at that stage (see Fig. 3A,B). The follicle cell layer is significantly thicker on the dorsal side in wild type, but there is a belt of closely spaced columnar follicle cells encircling the entire anterior end of the mutant $s q d$ oocyte.

The pattern of follicle cell gene expression also dorsalized at this time. A second chromosome lacZ enhancer trap line, PZ5650, generates high levels of $\beta$-galactosidase in the two patches of anterior dorsal follicle cells that will later make respiratory appendages (C. Berg, pers. comm.; see Fig. 3Cl. Staining sqd egg chambers carrying this enhancer trap with X-gal produces a ring of intensely stained follicle cells around the entire circumference (see Fig. 3D). This means that the activity of wild-type $s q d$ is required before this time, perhaps as the germinal vesicle completes its dorsal migration. The follicle cells of $K 10$ mothers display similar morphological defects reported here for sqd egg chambers (Wieschaus 1980).

\section{Ventralizing mutations are epistatic to sqd}

Double mutant combinations were constructed between sqd and K10. These females laid strongly dorsalized eggs, which was not surprising because each single mutant produces dorsalized eggs (see Table 2). More informative epistatic interactions were observed between $s q d$ and the ventralizing mutations $g r k$, top, and $c n i$. The three double mutants, grk sqd, cni sqd, and top sqd, each displayed ventralized chorions indistinguishable from ventralized mutants alone (see Table 2; Fig. 1E). Although interactions between hypomorphic mutations must be interpreted with caution, these data indicate that the dorsalized phenotype seen in sqd eggs requires the expression of wild-type $g r k, c n i$, and top. The top gene encodes a transmembrane tyrosine protein kinase similar to the vertebrate epidermal growth factor (EGF) receptor (Price et al. 1989; Schejter and Shilo 1989). The products of $c n i$ and grk are not known.

Df top/+; sqd/sqd females were expected to lay strongly dorsalized eggs like the one shown in Figure 1C. This was not the case. Instead, $\sim 60 \%$ of the eggs from individual females were normal length with a single respiratory appendage on the dorsal midline and resembled partially ventralized eggs from top/top mothers /see Fig. $1 F$; Table 2). Roughly $20 \%$ of the eggs had weakly dorsalized chorions and $\sim 5-20 \%$ displayed nearly normal morphology. Of 2625 eggs examined, 19 hatched as larvae, and 5 reached adulthood. Thus, the strongly dorsalized phenotype of $s q d$ eggs can be corrected and even reversed by reducing the number of EGF-like receptors on follicle cells by half. Null top mutations act as dominant suppressors of $s q d$, but hypomorphic point mutations in top do not (see Table 2). Cutting the dosage of top $p^{+}$by half has essentially no effect on $s q d^{+}$females; they remain fertile. The finding that $\sim 1 \%$ of sqd eggs can hatch if the dose of top ${ }^{+}$is reduced shows that mutant eggs retain some residual polarity.

Somewhat similar results were found with $g r k /+$; $s q d / s q d$ females. Their eggs were weakly dorsalized to

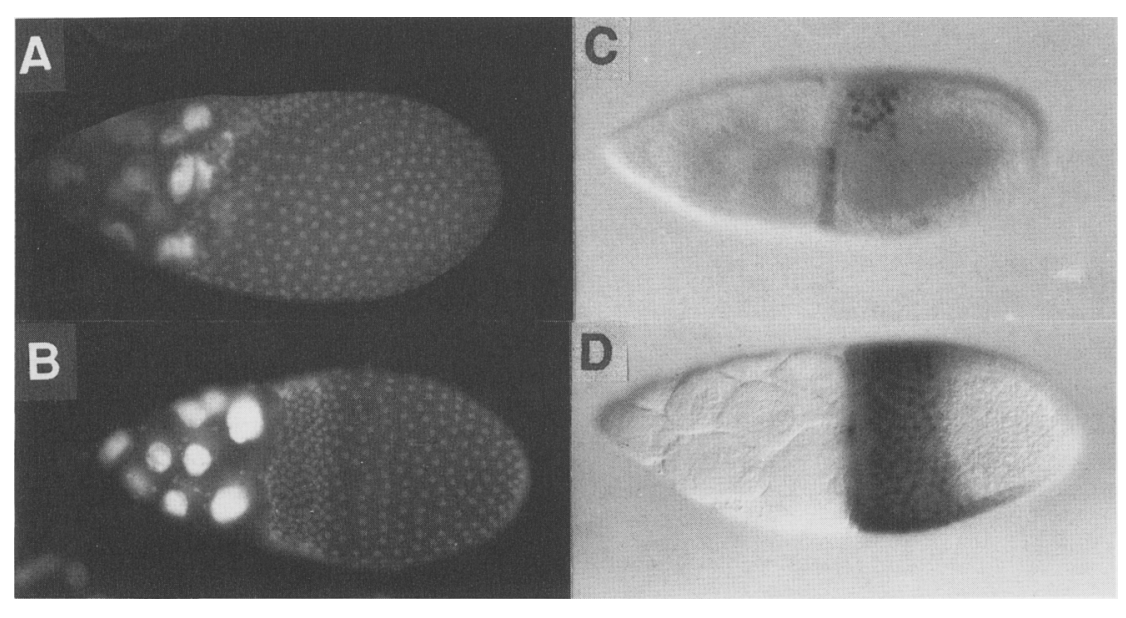

Figure 3. Morphology of egg chambers. In all cases, anterior (nurse cells) is to the left, posterior (follicle cell layer) is to the right, and dorsal is up. (A) DAPI-stained wildtype stage-11 egg chamber showing that only dorsal anterior follicle cells pack tightly together. $(B)$ Egg chamber of similar age from a $s q d^{1}$ female displaying a ring of densely packed follicle cells around the anterior end of the oocyte. (C) Wild-type egg chamber from a mother carrying the PZ5650 lacZ enhancer trap stained with $X$-gal showing that a group of dorsal anterior follicle cells produce $\beta$-galactosidase. (D) An egg chamber from a $s q d^{i \times 43}$ female carrying the PZ5650 enhancer trap stained with X-gal. All of the follicle cells probably adopt a dorsal fate. 
Table 2. Epistatic interaction between sqd and other genes in the dorsoventral pathway

\begin{tabular}{|c|c|c|}
\hline Maternal genotype & Egg morphology & Fertility \\
\hline $\begin{array}{l}+; s q d^{i \times 43} \\
+s q d^{i \times 28}\end{array}$ & D1 & $S$ \\
\hline $\begin{array}{l}\text { K10; } s q d^{i \times 43} \\
K 10 ; s q d^{i \times 43}\end{array}$ & D1 & $S$ \\
\hline $\begin{array}{l}\operatorname{grk}^{H K} ;+ \\
g r k^{W G}+\end{array}$ & $\mathrm{V} 2$ & $S$ \\
\hline $\begin{array}{l}c n i^{A A 112} ;+ \\
c n i^{A A 112}+\end{array}$ & $\mathrm{V} 2$ & $\mathrm{~S}$ \\
\hline $\begin{array}{l}\text { top }^{1} ;+ \\
\text { Df } c 18 A+\end{array}$ & $\mathrm{V} 2$ & $S$ \\
\hline $\begin{array}{l}\text { grk; } s q d^{i \times 43} \\
+\quad s q d^{i \times 43}\end{array}$ & $\mathrm{D} 2, \mathrm{D} 3,+$ & weakly fertile \\
\hline $\begin{array}{ll}c n i^{A A 112} ; s q d^{i \times 43} \\
+ & s q d^{i \times 28}\end{array}$ & $\mathrm{Dl}$ & $\mathrm{S}$ \\
\hline $\begin{array}{l}\text { Df c18A; } s q d^{i \times 43} \\
+\quad s q d^{i \times 28}\end{array}$ & $\mathrm{D} 2, \mathrm{D} 3,+, \mathrm{V} 2$ & weakly fertile \\
\hline $\begin{array}{l}\text { top }{ }^{1} ; s q d^{i \times 43} \\
+\quad s q d^{i \times 28}\end{array}$ & D1 & $S$ \\
\hline $\begin{array}{ll}\text { top }^{1} ; & s q d^{i \times 43} \\
\text { Df } c 18 A & s q d^{i \times 28}\end{array}$ & $\mathrm{~V} 2$ & $\mathrm{~S}$ \\
\hline $\begin{array}{l}g r k^{H K} ; s q d^{i \times 43} \\
g r k^{W G} s q d^{i \times 43}\end{array}$ & V2 & $\mathrm{S}$ \\
\hline $\begin{array}{l}c n i^{A A 112} ; s q d^{i \times 43} \\
c n i^{A A 112} s q d^{i \times 28}\end{array}$ & $\mathrm{~V} 2$ & $\mathrm{~S}$ \\
\hline
\end{tabular}

The egg morphology is scored as in Table 1: (D1) Strongly dorsalized; (D3) weakly dorsalized; (+) wild type; (V1) strongly ventralized (no respiratory appendage); (V2) weakly ventralized (single respiratory appendage on dorsal midline) (for examples of morphology, see Fig. 1). Females of each genotype were totally sterile (no egg ever hatched) with the exception of $D f \mathrm{c} 18 \mathrm{~A} / \mathrm{+}$; $s q d / s q d$ and $g r k /+; s q d / s q d$. Those females produced approximately $5-15 \%$ eggs with two respiratory appendages similar to wild-type eggs. Approximately $1 \%$ of the eggs hatched into larvae.

nearly wild type. No ventralized eggs were observed from such females. The finding that grk and top are weak dominant suppressors of sqd suggests that the corresponding gene products interact in a common pathway of axis formation in which the ratio of gene products is critical. Although the cni allele used was epistatic to $s q d$, it did not behave as a dominant suppressor of $s q d$ (see Table 2).

One further insight gained from these double mutants concerns the behavior of nurse cells. The successful transfer of nurse cell cytoplasm to the oocyte in grk sqd, cni sqd, and top sqd egg chambers proves that sqd is not needed for that process. Thus, the short egg phenotype of $s q d$ single mutants is not directly the result of any defect in nurse cells, and sqd is not a member of the "dumpless" class of female sterile mutations (Schüpbach and Wieschaus 1991; Cooley et al. 1992).

\section{Embryos from sqd mothers are dorsalized}

Eggs from females carrying the strong $s q d^{1}$ allele have nurse cell debris trapped within the cylindrical respiratory appendage and possibly defective micropyles. This blocks sperm entry, precluding recovery of embryos. However, the partially dorsalized eggs from mothers bearing weak alleles successfully inherit all of their nurse cell cytoplasm and are fertilized at high frequency. These embryos make dorsalized cuticles that consistently show reductions of the ventral denticle belts even if the sperm carry $s q d^{+}$(see Fig. $4 \mathrm{~B}, \mathrm{C}$ ).

\section{Cloning sqd}

The $s q d^{1}$ chromosome suffered a single P-element insertion as determined by in situ hybridization to polytene chromosomes (data not shown). The transposon landed at position 87F4-10, which is consistent with the cytological map position derived from deletion mapping (see Table 1). Moreover, when the original $s q d^{1}$ mutation

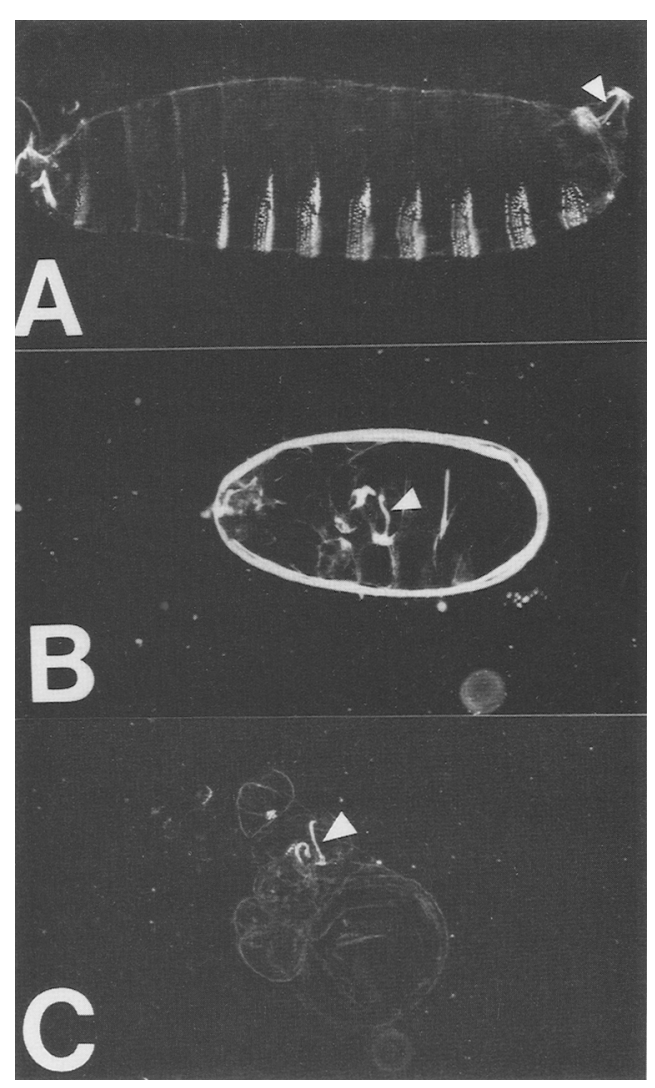

Figure 4. Cuticle preparations of wild-type and weak sqd embryos. (A) A wild-type embryo, with an arrowhead indicating the filzkörper. Anterior is left and dorsal is up. (B) Strongly dorsalized embryo from $s q d^{p \times 3} / D f$ urd mother within the vitelline membrane. The ventral denticle bands are absent and the cuticle is covered with fine dorsal hairs. The dorsally derived filzkörper are formed at the posterior end of even the most strongly affected animals. $(C)$ Strongly dorsalized embryo from $s q d^{K 12} / D f$ urd mother removed from the vitelline membrane. 
was crossed to a source of $\mathrm{P}$ transposase, ry excisions were recovered at high frequency and 49\% (96/197) of these reverted back to fertility, indicating precise removal of the transposon and proving that the $\mathrm{P}$ insert caused the mutant phenotype (see Fig. 5B).

DNA sequences flanking the $3^{\prime}$ end of the $r y^{+}$transposon in $s q d^{1}$ were amplified using inverse polymerase chain reaction (PCR), labeled, and used to screen a wildtype genomic cosmid library. Three overlapping clones were recovered that span a distance of $45 \mathrm{~kb}$. The location and polarity of the insertions were determined by genomic Southern blots, and the results are summarized in Figure 5A.

\section{sqd encodes a complex set of transcripts}

Several clones were recovered from an ovarian cDNA library using DNA flanking the P-element insertion site. The exons were mapped to the genomic cosmids by
Southern analysis, which revealed that the $\mathrm{P}$ element landed between two tightly linked genes, both of which are transcribed in ovaries. The cDNAs were used individually as hybridization probes to Northern blots of poly $(\mathrm{A})^{+}$RNA extracted from wild-type and sqd mutant ovaries. The cDNA clone mapping on one side of the insertion detects 4.2-, 3.7-, and 3.0-kb transcripts that are unaltered in sqd mutant ovaries and therefore unlikely to be produced by sqd (see Fig. 6B). This gene has not been analyzed and is referred to as $N$ ts (next to squid) for convenience.

cDNA clones mapping on the opposite side of the insertion hybridize to at least six ovarian transcripts of sizes $4.8,3.5,2.3,1.9,1.7$, and $1.5 \mathrm{~kb}$ (see Fig. 6A, lanes $2,3 \mid$. The structures of the sqd cDNA clones analyzed and the predicted structures of the major $s q d$ transcripts are summarized in Figure 6, D and F. The 3.5-, 1.9-, 1.7-, and $1.5-\mathrm{kb}$ mRNAs are dramatically reduced in abundance in sqd mutant ovaries. These four mRNAs are
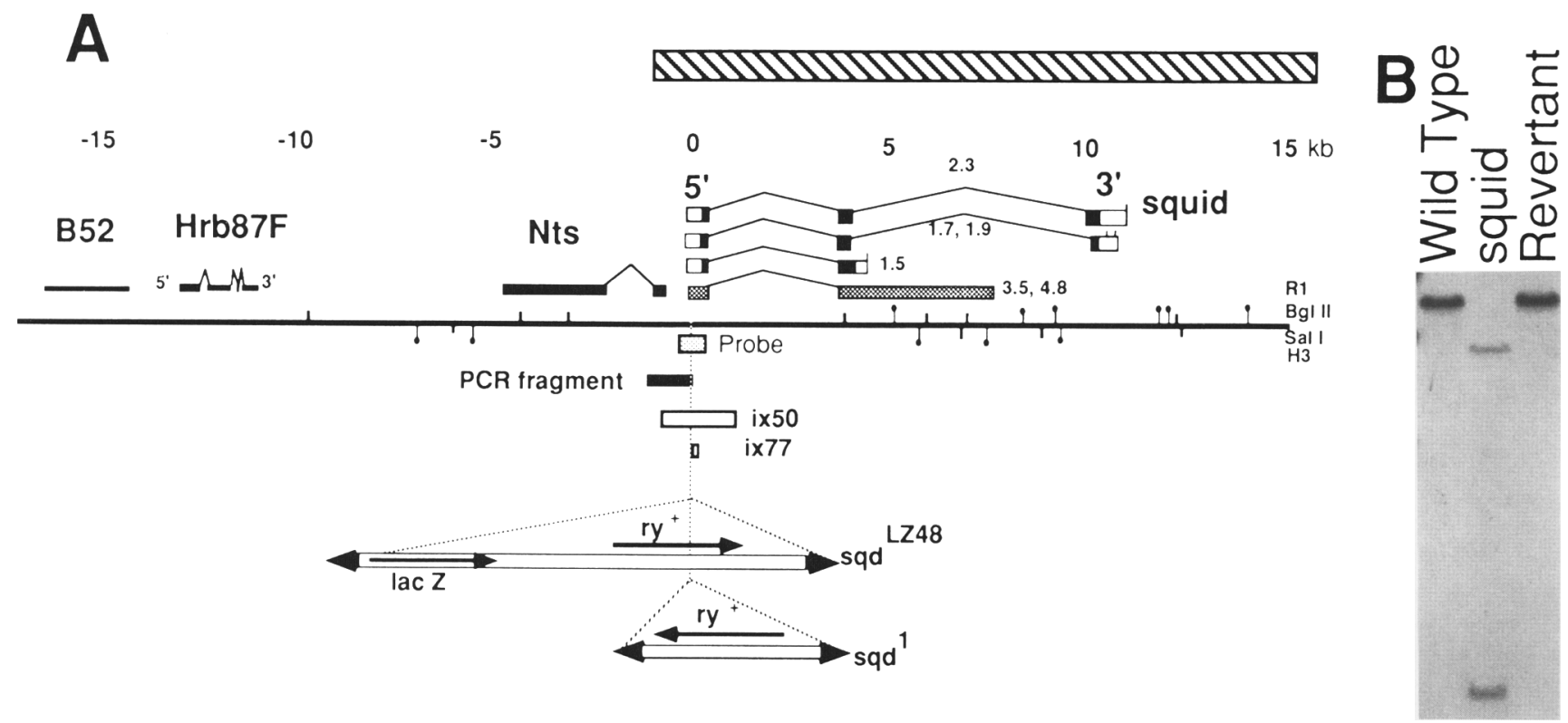

Figure 5. Structure of sqd gene. (A) A portion of the genomic DNA recovered in a cosmid walk is shown with the approximate locations of transcripts and transposon insertions. Restriction sites for EcoRI (R1, $\perp$ ); BgIII $(\perp)$; SalI ( T ); and HindIII (H3, T ) are indicated. The major alternative splicing patterns of the $s q d$ transcripts as deduced from cDNA clones are shown above the line, with the sizes of each one indicated. cDNA clones corresponding to the $2.3-\mathrm{kb}$ transcript were not isolated, but the transcript is thought to correspond to clone hrp 40.2 of Matunis et al. (1992b), and the presumptive structure is shown. Open boxes represent noncoding sequence; solid boxes are coding regions. Polyadenylation sites are indicated by short vertical lines extending above the $3^{\prime}$ exons. The locations of the 3.5- and 4.8-kb messages are deduced from Northern analysis and shown as shaded boxes because the coding potential is not known. Only the genomic DNA encoding the first exon was sequenced, so it is not known whether the other exons shown are interrupted by small introns. Nts is a tightly linked gene that has not been characterized. Hrb87F encodes an RNA-binding protein similar to sqd (Haynes et al. 1991; Matunis et al. 1992b). B52 encodes a chromatin binding protein (Champlin et al. 1991). The 1200-bp PCR fragment amplified from the $3^{\prime}$ end of the P element and used to isolate the cosmids is shown as a solid box adjacent to the insertion site. The DNA removed from the lethal imprecise excision, $s q d^{i x 50}$, and semilethal allele, $s q d^{i x 77}$, are shown as open boxes below the DNA. The P elements present in the $s q d^{1}$ and $s q d^{L Z 48}$ alleles are shown at bottom. The small shaded box spanning the insertion site is the 650-bp probe used for the genomic Southern shown in $B$. The hatched box at top indicates the $16 \mathrm{~kb}$ of genomic DNA that rescues the viability and fertility of $s q d$ mutations when introduced by P-element transformation. $(B)$ A genomic Southern blot of the parental wild-type strain, $s q d^{2}$, and the fertile precise excision $s q d^{r 5}$ cut with HindIII and BamHI. The filter was hybridized with a 650-bp genomic restriction fragment containing the first sqd exon shown as the shaded box in $A$. Because the P element has HindIII sites at each end, the wild-type $8.2-\mathrm{kb}$ BamHI genomic fragment is split into $5.9-$ and $2.3-\mathrm{kb}$ fragments. The similar hybridization intensity of the two mutant bands means that the insertions are near the middle of the interval defined by the probe. 
Figure 6. Northern analysis of sqd transcripts. (A) Approximately $3 \mu \mathrm{g}$ of poly $(\mathrm{A})^{+}$ RNA was loaded on each lane and hybridized to a portion of a $s q d$ cDNA. The RNA was isolated from the following sources: (Lane 1) Adult wild-type males; (lanes 2, 10-14) wild-type ovaries; (lane 3) ovaries from $s q d^{1} / s q d^{L Z 48}$ females; (lane 4) whole adult $0 v o^{D}$ females; (lane 5) 0- to 3 -hr wildtype embryos; (lane 6) 4- to 24-hr wild-type embryos; (lanes 7-9) wild-type first-, second-, and third-instar larvae, respectively. Lanes 1-9 were hybridized with the nearly full-length pSCl.4 cDNA probe contained the RNP-coding domain. Lane 10 was hybridized with probe $a$, a 620-bp fragment covering the 5' sqd exon; lane 11 was hy-

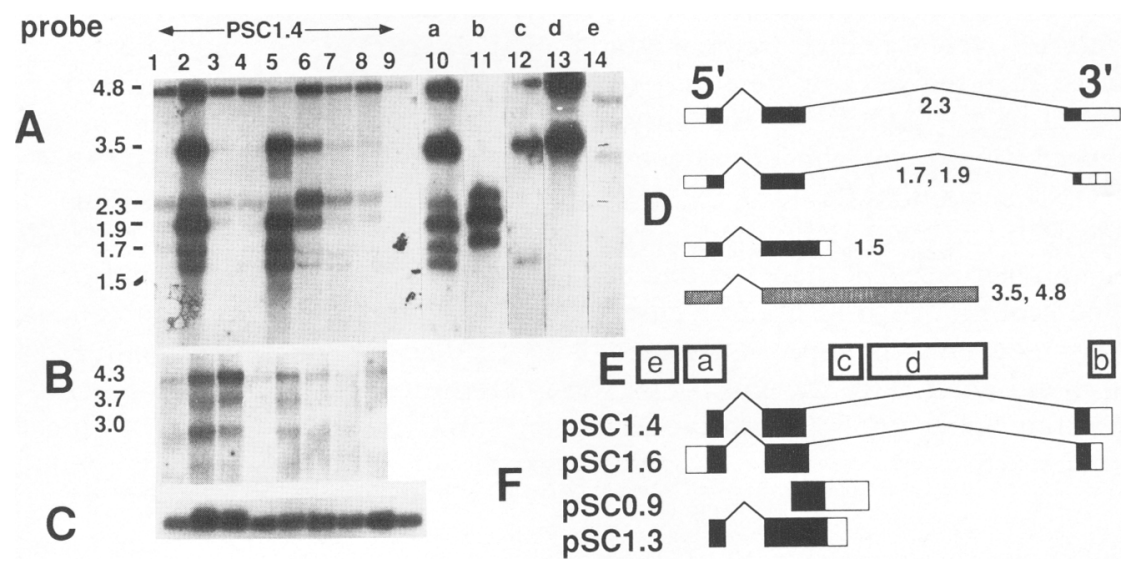
bridized with 370 -bp probe $b$ derived from the alternative $3^{\prime}$-untranslated region in $s q d B$; lane 12 was hybridized to probe $c$, a 530 -bp fragment from the alternative $3^{\prime}$ exon in $s q d A$; lane 13 was hybridized to a $3.2-\mathrm{kb}$ EcoRI fragment at genomic coordinates $5.5-8.5$ in Fig. 5, probe $d$; lane 14 was hybridized with probe $e$, a 1.2-kb genomic fragment immediately 5 ' of the sqd promoter. $(B)$ The same filter as in $A$ (lanes 1-9) was stripped and rehybridized with a 3-kb cDNA clone of Nts. (Note that there is no difference between the ovarian transcripts observed in wild-type or sqd mutants.) (C) The same filter hybridized with an anonymous cDNA, detects a transcript in all developmental stages showing that each lane contained RNA. $(D)$ The structures of the sqd transcripts deduced from Northern blots and cDNA sequences. The 1.5-kb mRNA encodes SqdA. The 1.7- and 1.9-kb transcripts encode SqdB protein but differ in the polyadenylation site chosen. The 2.3-kb somatic transcript encodes SqdS (Matunis et al. 1992b). The exact structure of the 3.5- and $4.8-\mathrm{kb}$ transcripts is not known. Solid boxes indicate coding sequence, open boxes indicate noncoding, and shaded boxes indicate unknown coding capacity. $(E)$ The locations of the hybridization probes used in $A$ aligned to the transcripts shown in $D$ and $F$. $(F)$ The structures of $s q d$ cDNA clones characterized for this paper. Solid boxes indicate coding; open boxes indicate noncoding.

transcribed primarily in ovaries because they are present only at the limit of detection in wild-type larvae, adult males, or ovo $^{D 1}$ adult females that have rudimentary ovaries (see Fig. 6A, lanes 1-9). The 4.8- and 2.3-kb transcripts are only slightly reduced in abundance in sqd ovaries. Their presence in nonovarian tissues is consistent with genetic analysis indicating additional functions for sqd. All of the transcripts are present in 0- to 3 -hr embryos, showing that they are maternally inherited (see Fig. 6A, lane 5). The $s q d^{L Z 48}$ enhancer trap allele makes $\beta$-galactosidase predominantly in germ cells as opposed to follicle cells, suggesting that the ovary-specific $s q d$ transcripts are germ cell products (see Fig. 2A).

The $s q d$ cDNA clones were found to contain one of two alternative $3^{\prime}$ exons. Three of the transcripts $(2.3$, $1.9,1.7 \mathrm{~kb}$ / hybridized with one alternative 3 ' probe, and the remaining three $(4.8,3.5,1.5 \mathrm{~kb})$ hybridized to the other $3^{\prime}$ exon on Northern blots (Fig. 6A, lanes 10-12). This shows that all messages are derived from the same gene by differential RNA processing. Incomplete cDNA clones corresponding to the $4.8-$ and $3.5-\mathrm{kb}$ transcripts have not been characterized in detail. However, Northern analysis of ovarian RNA revealed that the additional exons lie between coordinates 6 and 9 on the genomic walk (Fig. 6A, lane 13).

A 16-kb fragment of wild-type DNA spanning the presumed sqd gene was inserted into a P-element vector and used to transform flies (see Fig. 5). This DNA rescues the fertility of $s q d^{1}$, the viability and egg polarity of $s q d^{i \times 50} /$ Df urd, and both the viability and fertility of $s q d^{i \times 50} /$ $s q d^{i \times 77}$ animals, proving that this is the complete $s q d$ gene.

\section{Sqd is similar to a family of RNA-binding proteins}

The nucleotide sequences compiled from cDNA clones and genomic DNA near the $5^{\prime}$ end of the gene are presented in Figure 7 along with the conceptual translation. The longest cDNA clone recovered begins at +80 in good agreement with the sizes of the four smaller transcripts observed on Northern blots. The sequence TATAAA is located $\sim 40$ nucleotides upstream of the presumed transcription start site determined by nuclease protection analysis (data not shown). The P elements in $s q d^{1}$ and $s q d^{L Z 48}$ both inserted near +255 as determined by genomic Southern blots and PCR analysis (data not shown).

The first ATG codon at nucleotide 121 is quickly followed by stop codons in all three reading frames. The next ATG at 405 displays a good match to the Drosophila consensus translation start site (Cavener 1987) and is followed by an open reading frame encoding either a 321- or 308-amino-acid-residue protein (SqdA and SqdB, respectively), depending on the splicing pattern.

These predicted proteins were found to have an imperfect duplication of a 76-residue domain that is similar to a large class of single-stranded nucleic acid-binding proteins (Bandziulis et al. 1989; Nagai et al. 1990). The carboxy-terminal portion of the protein is $45 \%$ glycine, similar to other RNA-binding proteins (Cobianchi et al. 1986; Haynes et al. 1991), and the RGG repeats (residues 224-243) may provide a third RNA-binding domain (Kilediian and Dreyfuss 1992; Ghisolfi et al. 1992). This glycine-rich domain continues until almost the end of the SqdB polypeptide, but in SqdA the last 22 residues 


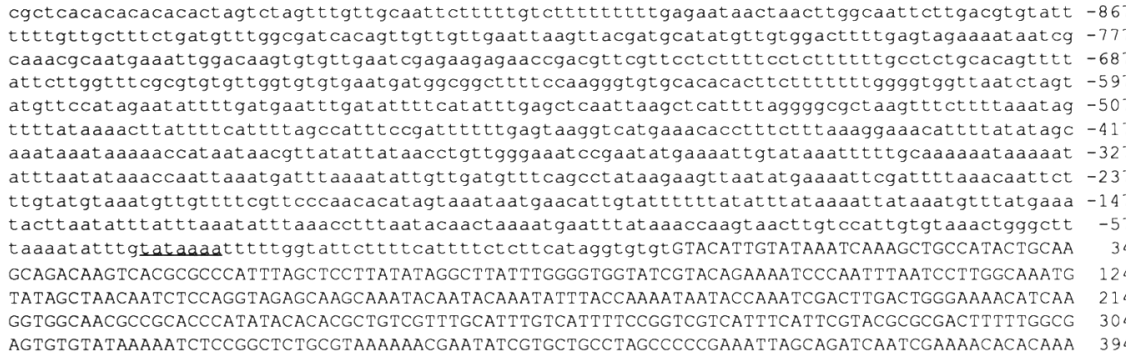

ATGGCCGAGAACAAGCAAGTGGATACAGAAATAAACGGCGAGGATTTCACCAAGGACGTGACTGCCGACGGTCCGGGATCTGAAAATGGT

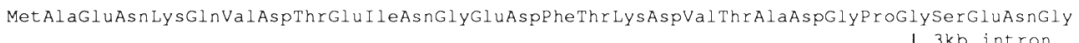
TaGGACTGTTTGTC AspAlaGlyAlaAlaGlySerThrAsnGlySerSerAspAsnGlnSerAlaAlaSerGlyGlnArgAspAspAspargLys LeuPheVal

GGTGGTCTGAGCTGGGAAACGACTGAGAAGGAACTCCGCGATCACTTCGGCAAATATGGCGAGATCGAGAGCATCAATGTCAAGACAGA?

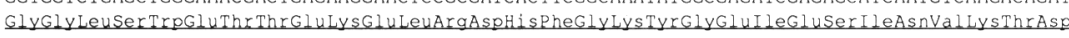

CCCCAGACCGGTCGGTCCCGAGGATTCGCCTTCATCGTGTTTACAAACACCGAGGCCATTGACAAAGTCAGCGCCGCGGATGAGCACATA ProGlnThrGlyArgSerArgGlyPheAlaPheIleVal PheThrAsnThrGluAla IleAspLysVal SerAlaAlaAspGluHis Ile

ATCAACAGCAAGAAGGTCGATCCCAAGAAGGCCAAGGCCAGGCACGGCAAGATCTTTGTCGGCGGCCTCACCACAGAGATCAGCGATGAG

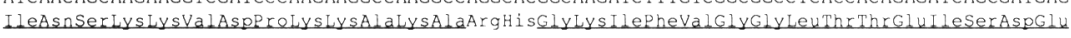

GAGATTAAGACCTACTT TGGACAGTTCGGCAATATCGTCGAGGTGGAGATGCCACTCGACAAGCAAAAGTCGCAGCGCAAAGGATTCTGC

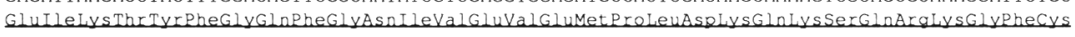

TTCATCACCTTCGATTCGGAGCAGGTGGTGACGGATT TGCTGAAGACGCCCAAGCAGAAGATCGCCGGCAAGGAGGTCGATGTTAAGCGT 1024

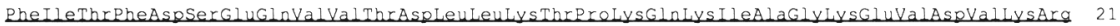
GCGACGCCCAAGCCGGAGAACCAGATGATGGGCGGTATGCGTGGTGGACCACGCGGTGGTATGCGCGGCGGACGCGGTGGCTACGGAGGA 1114 AlaThrProlys ProGluAsnGInMetMetGlyGlyMetArgGlyGlyProArgGlyGlyMetArgGlyGlyArgGlyGiyTyrGlyGly 240 Pro

CGAGGTGGCTACAACAACCAGTGGGACGGACAGGGATCATACGGCGGCTATGGCGGCGGCTACGGCGGATATGGTGCCGGTGGTTATGGC 120

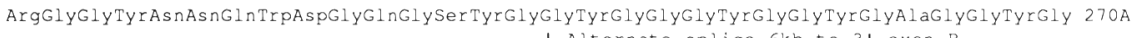

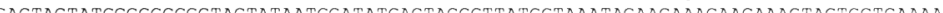

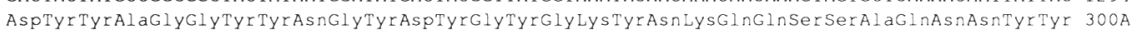
AAT AACAACACGTCGAGTAATTACCATCAAAACAAGAACAATAGCAACAACTATCAGCAGTTCTAAGT AGAGCCTCAGCCGCATAGACGT 1384

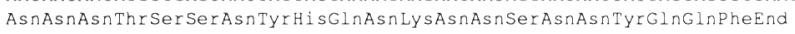

GGCCTGGCCTGGCCAGCAACAAAATCAGAAAGAAATAATCAAACAAAGCAAACAACAACAACCGCAGAATATAAAAACC TTCTATTTTTC 1474 CCATAGACCTGATCTGATCCAAAATTTCCACGTTGTTGTGTTTCCCATTCAAACAAAACTGAGAGAAAAAACAAAAACAAAAGTTTAGCT 1564 GCATTTCGATATATAGTACCATATATATATATATATATATTTATATATGCTTATATACCGCATGCATTGTCTATATGCATATTTGCATAT 1654 AAATCATCTTCCTATATCATCTCAATCAACAACAACATCAAAAACAACAACAACAACAACAAAACTACCAAACCAACCTCCCTAAAAC 1744 AACAAAACTTTTAAAAATCTACATTMCAAAGACACAAACAACAAACA

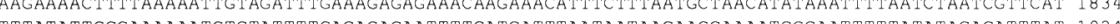
TTTATATTGCGAAAAATGTCTATTTTGACAGACAATTTTCATCATTTAATAATAACAAGCAAAATCGCAATTTTTATATACACATTTAT 1924
ATCTATCTTATTAAATATAAACCTACGTATAATTTAAAGGC

Alternative $3^{\prime}$ exon for sqdB protein

GCGGTGGCGGTTTTAACGGTGGCAAGCAGCGCGGAGGCGGTGGACGCCAGCAGCGGCATCAGCCCTACTAAAAAGTGGGCAGGGGGCGTG 1339 GIYGIYGIYGIYPheAsnGlyGlyLysGInArgGIYGIYGIYGIYArgGInGInArgHisGlnProTyrEnd

GGCATTGGGTATCTCGCATTCTCCGGATAACTGCAAACTATTTGAATTTTACCTAGTTTAGTTTGTTATGCATTACTACAAGAAGCAACAC $1429^{\prime \prime}$ ACATCTCTGCAACAACACCATCTGGGTAACCGCATATATACATACGCCGTTGTATATATCTGTATGAAAGAAATGAGGAAAAAAGGAAATG $1519^{\circ}$ ATAGACTGGCTGGCTGGGAGCAATAATATCAACATCAGCAACCTTAACACACCTTTACACACTTGATGTGTAGCACCATTCCAACAACAGC $1600^{\circ}$ ATCATACGCAGCTAAAAAACATCATTTATACAATACAAGGCAAACCACAAAGC
Figure 7. The sequence of sqd. The sequences derived from cDNA clones pSC1.4, pSC1.6, and pSC0.9 and the genomic DNA around the $5^{\prime}$ end of the gene. Transcribed sequences are shown in uppercase letters, and nontranscribed $5^{\prime}$ sequences are shown in lowercase letters. The $5^{\prime}$ end is only known to within $\sim \pm 7$ nucleotides from nuclease protection assays; so the assignment of nucleotide +1 is arbitrary. The longest cDNA begins at +72 . The sequence TATAA is located at -45 to -39 (underlined). A second TATAA box is located at +310 , but no initiation at that site was detected by nuclease protection assays /data not shown). The insertion sites of the P elements in $s q d^{1}$ and $s q d^{L Z 48}$ are near position +251 . The long open reading frame begins with an ATG codon at 395. The first intron is located at 561, which is also the beginning of the first RNA-binding domain. The second exon is sometimes spliced at 1250 to attach an alternative $3^{\prime}$ exon. The SqdA-coding region continues to 1356. The alternative SqdB-coding region terminates at $1317^{\prime}$. The two RNA-binding motifs are underlined. Nucleotide 1077 is $\mathrm{G}$ in two cDNAs and C in another, resulting in an arginine-to-proline substitution. It is not known if this represents a polymorphism in the stock from which the cDNA library was constructed or a reverse transcription error, but Matunis et al. (1992b) report a $\mathrm{G}$ at this site. are replaced with 35 residues that lack glycine and are 95\% hydrophilic. As this paper was being prepared, Matunis et al. (1992a,b) reported the cloning and sequencing of two cDNA clones encoding isoforms of a Drosophila heterogenous nuclear ribonucleoprotein (hnRNP), Hrp40. The predicted amino acid sequence of one of these proteins (321 amino residues long) is identical to SqdA and maps to position $87 \mathrm{~F}$, proving that hrp40 and sqd are the same. The second isoform of Hrp40 is similar to SqdB except that it contains a $37-$ codon glycine-rich insertion between residues 285 and 286 (Matunis et al. 1992b). This cDNA also continues another 357 nucleotides beyond the $3^{\prime}$ end of the sequence reported here and probably corresponds to the somatic $2.3-\mathrm{kb}$ transcript.

The most similar Drosophila gene $142 \%$ identity over both RNP domains) reported is $\mathrm{Hrb87F}$ encoding a ho- molog of the vertebrate A and B hnRNP proteins (Haynes et al. 1991; Matunis et al. 1992b). The Hrb87F gene maps to restriction fragments $10-13 \mathrm{~kb}$ away from the $s q d^{1}$ insertion site ( $\mathrm{S}$. Haynes, pers. comm.; see Fig. 5A). A third gene, B52, encoding a chromatin-binding protein with a single, highly divergent RNP-like domain, has been described recently by Champlin et al. (1991) and is adjacent to the $H r b 87 F$ gene (Fig. 5).

\section{Discussion}

The sqd gene is needed to organize the D/V axis during oogenesis, judging from the alterations in follicle cell behavior in sqd mutants. P-element insertions in the $5^{\prime}$ end of the gene result in dorsalized eggs and a corresponding reduction in the four ovary-specific sqd transcripts. Matunis (1992) has shown that this mutation 
eliminates the intense Sqd/Hrp40 staining in nurse cells and oocyte, but the follicle cell staining remains. Although the maternal function of $s q d$ is to help organize $\mathrm{D} / \mathrm{V}$ axis of egg chambers, it also has a somatic role because the strongest alleles are lethal and two of the transcripts are found in nonovarian tissues.

The $s q d$ gene employs alternative RNA splicing to encode at least three proteins $(345,321,308$ amino acid residues; SqdS, SqdA, SqdB, respectively). Both the SqdA and $\mathrm{SqdB}$ isoforms are encoded by ovarian transcripts that are greatly reduced in abundance by the transposon insertions. Either or both may be needed for axis formation. On the other hand, the $2.3-$ and $4.8-\mathrm{kb}$ somatic transcripts are only slightly reduced in the viable female sterile alleles of $s q d$, suggesting that they play little or no role in $\mathrm{D} / \mathrm{V}$ axis formation.

Each isoform shares the first 285 amino acid residues (this paper; Matunis et al. 1992b). This common aminoterminal domain contains two RNA-binding motifs, and Matunis et al. (1992a,b) have shown that these proteins are major components of hnRNP complexes. The isoforms differ in the carboxy-terminal glycine-rich domain whose function is not known, although it might alter the RNA-binding properties or subunit assembly potential of the polypeptides (Matunis et al. 1992b) or subcellular distribution. Animals carrying lethal mutations in sqd survive through the larval period perhaps using the pool of maternally inherited Sqd proteins. They may die after this is exhausted as a result of a failure in some step in hnRNA processing. The precise biochemical functions of hnRNP proteins are not understood (Bandziulis et al. 1989 |, but these lethal mutations in sqd provide a new opportunity to investigate their function in vivo.

\section{A model for $D / V$ axis formation}

The nearly 20 characterized genes that are required in the mother for proper $\mathrm{D} / \mathrm{V}$ axis formation fall into two classes (Anderson 1989). The late-acting genes utilize extraembryonic spatial information to direct formation of the embryonic D/V axis. Mutations in these genes affect only the polarity of the embryo but not that of the chorion. Mutations in the early genes alter the polarity of both the embryo and the surrounding egg shell. They seem to act around stages 8-10, midway through oogenesis, to polarize the developing egg chamber by transmitting a signal between the oocyte and the surrounding follicle cells (Schüpbach 1987; Prost et al. 1988; Montell et al. 1991). Manseau and Schüpbach (1989) have proposed that a signal [here called dorsalizing morphogen $\mathrm{DM}]$ is made in the growing egg chamber. Laser ablation studies of Montell et al. (1991) indicate that the germinal vesicle is either the site of synthesis or accumulation of the dorsalizing signal. DM activity requires the grk and cni genes (Schüpbach 1987; Ashburner et al. 1990), and the capu and spir genes seem to play some role in transport or localization of macromolecules, including K10 transcripts (Manseau and Schüpbach 1989; Cheung et al. 1992). DM may induce follicle cells to adopt a dorsal fate perhaps by serving as the ligand for the EGF-like receptor encoded by top (Schüpbach 1987; Clifford and Schüpbach 1989; Price et al. 1989; Schejter and Shilo 1989). The fate of individual follicle cells would depend on their distance from the source of morphogen, presumably the germinal vesicle (Montell et al. 1991). This model is illustrated in Figure 8.

One of the follicle cell responses to this transient signal may be to regulate the synthesis of a second, longlasting ventralizing factor thought to be inserted into the vitelline membrane as it is being secreted onto the surface of the oocyte (Stein et al. 1991; Stein and NüssleinVolhard 1992). This signal is needed later at blastoderm to produce active Tl ligand ventrally (Chasan et al. 1992).

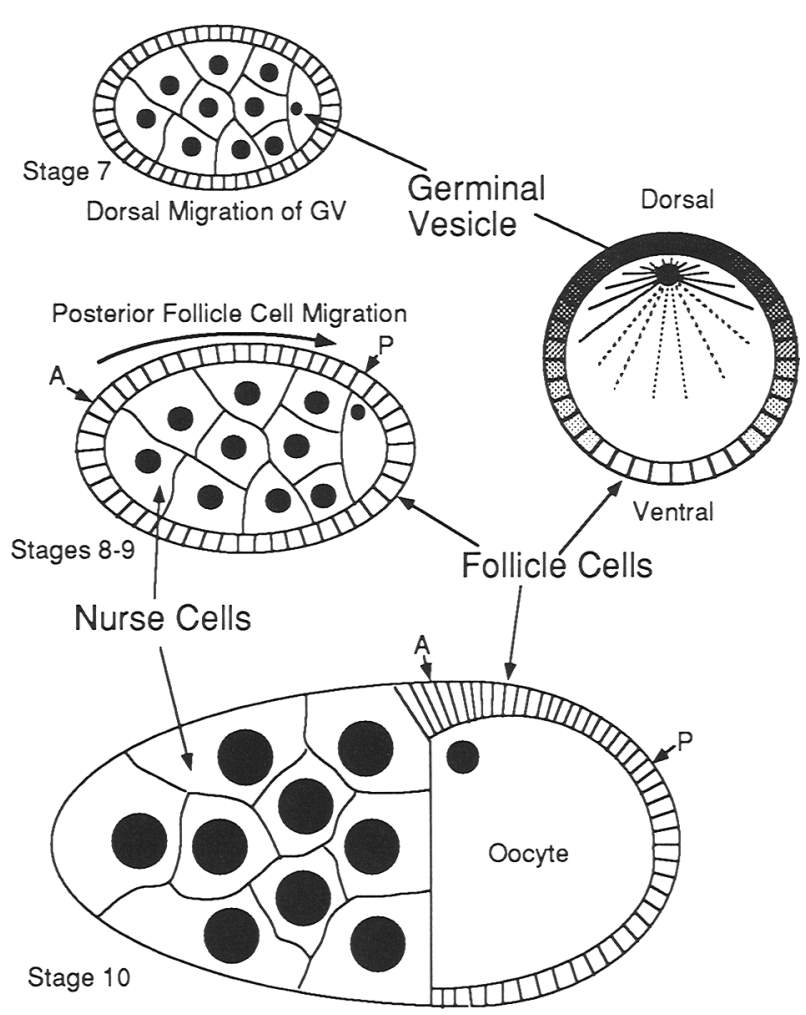

Figure 8. Model of $\mathrm{D} / \mathrm{V}$ axis formation /Manseau and Schüpbach 1989; Montell et al. 1991). Lateral views of egg chambers at the time of $\mathrm{D} / \mathrm{V}$ axis determination are shown at left. The germinal vesicle $(\mathrm{GV})$ migrates to the presumptive dorsal pole by the end of stage 8 . The follicle cells then migrate posteriorly and pass over the GV. Posterior follicle cells $\langle\mathrm{P}\rangle$ are in close contact with the GV and may become polarized first. The anterior follicle cells (A) do not come in contact with the oocyte until this migration is complete and so might acquire $D / V$ fate last. A cross section through an egg chamber at the time $D / V$ axis is determined is shown at right. The GV is the black dot near the top, and the monolayer of follicle cells surrounds the oocyte. The lines radiating from the GV indicate the path that the postulated dorsalizing morphogen would take to reach the follicle cells. Follicle cells with a dorsal fate are dark, and those with a ventral fate are shown white. DM is thought to reach even the ventral follicle cells in sqd mutants either because DM is overproduced or DM transcripts are free to diffuse away from the dorsal pole before translation. 
In this model ventral fate is the default developmental pathway taken by follicle cells that do not receive the dorsalizing signal (Montell et al. 1991). Ventralized eggs are produced in mutants unable to make DM (like grk or cni?) or in mutants such as top whose follicle cells are unable to respond to the signal (Schüpbach 1987). How, then, can a dorsalized phenotype result from the loss-offunction mutation in $K 10$ or $s q d$ ? The simplest interpretation is that $K 10$ and sqd encode negative regulators of the DM or are required to limit its distribution. Removing either regulator results in more widely distributed DM so that follicle cells adopt a dorsal fate regardless of their actual location. The observation that the dorsalized sqd phenotype requires the wild-type activity of top, cni, and grk is consistent with such a model.

Two molecular models of $s q d$ action seem plausible based on the finding that it encodes an RNA-binding protein. In the first model, Sqd acts as a nuclear RNA processing factor. Matunis et al. (1992a) have shown that Sqd/Hrp40 is primarily nuclear in some somatic cells and binds to most nascent transcripts on polytene chromosomes. Recently, Mayeda and Krainer (1992) showed that a similar vertebrate hnRNP protein, Al, can determine which of two alternative $5^{\prime}$ splice acceptor sites is chosen by antagonizing the SF2 splicing protein. Several developmental processes in Drosophila are regulated at the level of RNA processing (Bell et al. 1988; Nagoshi et al. 1988; for review, see Laski et al. 1986; Robinow et al. 1988; Baker 1989). In this model the Sqd target would be the DM primary transcript. If Sqd normally down-regulated DM by inhibiting the maturation, transport, or translation of some fraction of DM transcripts, then all DM transcripts would be functional in sqd mutants, leading to overproduction of morphogen.

An alternative view is that Sqd/Hrp40 could act as a cytoplasmic RNA localization factor that would sequester DM mRNA in the dorsal pole of the egg, near the germinal vesicle. All DM translation would occur dorsally resulting in a protein concentration gradient decreasing ventrally. This gradient would be more shallow in $s q d$ mutants because the DM RNA could diffuse away from the dorsal pole before translation. There is a thick network of microtubules encircling the germinal vesicle (Theurkauf et al. 1992) that could anchor Sqd-RNA complexes to the dorsal pole of the oocyte.

Similar mechanisms have been described for localizing the RNAs encoding the anterior (bcd) and posterior (nos) morphogens. They are delivered to small areas at the egg's poles during oogenesis and retained there presumably by RNA-binding proteins tethered to cytoskeletal elements (St. Johnston et al. 1989, 1991; Ephrussi et al. 1991; Kim-Ha et al. 1991). Anterior localization of bcd RNA depends on swallow (swa) and exuperantia (exu) (Stephenson et al. 1988; Macdonald et al. 1991), and mutations in either gene result in a more evenly distributed $b c d$ product (Frohnhöfer and Nüsslein-Volhard 1987). Localized maternal mRNAs in vertebrates have also been reported and are thought to be transported and held in place by RNA-binding proteins attached to the cytoskeleton (Mowry and Melton 1992).
If the Sqd isoform active in $\mathrm{D} / \mathrm{V}$ polarity were an RNA processing factor, it would most likely be nuclear, whereas the RNA localization model predicts predominantly cytoplasmic Sqd protein. Matunis (1992) has demonstrated that the spatial distribution of Hrp40 antigen is extremely dynamic during oogenesis with both nuclear and cytoplasmic Hrp40 staining at different stages. Unfortunately, those results cannot distinguish between the two models because the antibody used recognizes all Hrp40 isoforms, not just those involved in D/V axis formation.

The processing model predicts that total synthesis of DM goes up in sqd mutants. The localization model predicts that the distribution, but not the total amount, of DM is altered. The double mutant results reported here show that dorsal follicle cells can adopt the correct fate even if they have only half the number of Top receptors as long as the female is $s q d^{+}$. However, these dorsal follicle cells often fail to become fully dorsalized in $D f$ top $/+$; sqd/sqd females. One way to interpret this unexpected ventralized phenotype is to postulate that the DM concentration around the germinal vesicle $(\mathrm{GV})$ is actually lower in $s q d$ mutants rather than higher. This could occur if DM transcripts were free to diffuse into the ventral region of the oocyte, thus depleting the dorsal concentration. The reduced DM concentration released from the dorsal region of the oocyte would be insufficient to induce follicle cells with half the number of receptors to enter a dorsal fate. However, other interpretations of these result are possible; so both models of sqd action must be considered until the gene encoding DM is available to directly test them.

One apparent paradox of this model is how a protein that recognizes sequences in many nascent transcripts (Matunis et al. 1992a) could specifically bind to only DM transcripts in oocytes. The germinal vesicle is thought to transcribe very few genes at the time the $D / V$ axis is organized (King and Burnett 1959; Mahowald and Tiefert 1970; Prost et al. 1988; Montell et al. 1991). If mature DM mRNAs retain a Sqd-binding site, it may suffice to ensure perinuclear localization. The apparent target specificity would simply result from the limited repertoire of germinal vesicle transcripts. Alternatively, the sequence differences at the glycine-rich carboxyl ends of the various Sqd isoforms may confer greater RNA-binding specificity to the isoforms acting in $\mathrm{D} / \mathrm{V}$ patterning.

\section{Materials and methods}

Fly stocks

All fly stocks used carried markers described in Lindsley and Zimm (1992). An isogenic stock free of recessive lethal or sterile mutations marked with $c n$; ry $c v-c s b d$ was mutagenized with a single X-linked P element marked with $\mathrm{ry}^{+}$as described (Cooley et al. 1988, 1989), except that the $\Delta 2-3$ element was used as the source of transposase (Robertson et al. 1988). A total of 3578 crosses was screened that produced 2895 independent males with an autosomal ry ${ }^{+}$insertion. sqd $d^{1}$ was one of 25 female sterile lines recovered. Allan Spradling (Carnegie Institute of Washington, Baltimore, MD) and Trudi Schüpbach 
(Princeton University, NJ) each supplied independently isolated enhancer trap insertions with lacZ-marked $\mathrm{P}$ elements, $L Z 48$ and $A N 240$, respectively. Trudi Schüpbach also supplied the weak ethylmethane sulfonate (EMS)-induced $s q d^{K 12}$ allele. Imprecise excisions were generated by crossing the $s q d^{1}$ stock to $\Delta 2-3$ jumpstarter and recovering ry sons. Of 197 excisions tested, $96(48 \%)$ were apparent precise excisions and reverted to full fertility and normal polarity; $74(37 \%)$ retained the dorsalized phenotype and were scored as imprecise excisions. Genomic Southern blots showed that most of these suffered internal deletions within the ry-coding region but did not remove flanking fly DNA. Three of these excisions $(i x 50,65,77)$ removed flanking sqd sequences. Only ix 50 was found to delete sufficient flanking DNA to remove the $5^{\prime}$-most $s q d$ exon, but this deletion may extend into Nts. The remaining 27 excisions $(13 \%)$ expressed weakly dorsalized phenotypes that were very sensitive to gene dosage like the $s q d^{K 12}$ allele. These excisions were fertile as homozygotes but semisterile or completely sterile when hemizygous and were scored as partial revertants.

Double mutants between sqd and $f s(1) K 10$, grk, top, or cni were constructed using standard crosses. The genotypes of the final progeny were determined by using tightly linked visible markers. More than 20 double mutant females were examined in each case, and all individuals that were assigned the same genotype displayed the same phenotype.

\section{In situ hybridization}

The location of the $s q d^{1}$ insertion was determined by hybridizing biotinylated ry DNA to polytene chromosomes of mutant larvae (Langer-Safer et al. 1982).

\section{Cloning sqd}

Total genomic DNA from $s q d^{1}$ adults $(\sim 20 \mathrm{ng})$ was cut to completion with Sau3A, ligated into small circles under dilute conditions, and then cut with HindIII. Only the fragment derived from the junction between the $3^{\prime}$ end of the P element and sqd-flanking DNA would have known sequences from the $\mathrm{P}$ element at each end. That fragment was amplified by PCR using an oligomer for the inverted repeat at the end of the P element, 5'-CGATCGGGACCACCTTATGTTATTTCATCAT-3', and one derived from the $3^{\prime}$ end of the ry sequence, $5^{\prime}$-AAGGCACAATGTTCCATGGCGTAAATGATC-3'. The resulting 1.2$\mathrm{kb}$ amplified fragment was labeled by random priming and used to screen a wild-type Drosophila genomic cosmid library in the cosPneo vector (Steller and Pirrotta 1985). The three cosmids recovered were restriction mapped, and the insertion site was determined by hybridizing the labeled $1.2-\mathrm{kb}$ PCR fragment to restriction digests of the cosmids. The cDNAs were isolated from a library supplied by the late Laura Kalfayan prepared with ovarian mRNA. Two of the cDNA clones, $\mathrm{pSCl} .4$ and $\mathrm{pSCl}$.6, were found to contain foreign sequences not derived from the $87 \mathrm{~F}$ region of the chromosome and were presumably the result of ligation between $s q d$ cDNAs and unrelated cDNAs during library construction. The $s q d$ cDNA clones pSC1.6, pSC1.4, pSC1.3, and pSC0.9 and a $1.9-\mathrm{kb} \mathrm{XbaI}$ genomic fragment surrounding the P-insertion sites were each cloned into Bluescript $\mathrm{SK} \mid+1$. Sets of nested deletions were constructed from each plasmid using exonuclease III as described (Sambrook et al. 1989). Each clone was sequenced using Sequenase (U.S. Biochemical) following the supplier's protocol lexcept pSC1.3, only the ends of which were sequenced).

The approximate location of the $\mathrm{P}$ elements in $s q d^{1}$ and $s q d^{L Z 48}$ were determined by genomic Southern blots. More precise localization was done by PCR amplification of the genomic
DNA between the inverted repeat of the $\mathrm{P}$ elements and a known sequence within the $5^{\prime}$ exon of $s q d$. The primers used were at the end of the P element and at +460 of sqd, 5'CGATCGGGACCACCTTATGTTATTTCATCAT $-3^{\prime}$ and $5^{\prime}$ CGGCAGTCACGTCCTTGGTG-3', respectively. The reactions were done essentially as described above except that $\left[\alpha^{-32} \mathrm{P}\right] \mathrm{dCTP}$ was included in the reaction and the bands were resolved on a polyacrylamide sequencing gel for better size resolution.

\section{Southern and Northern blots}

Genomic DNA was prepared by homogenizing flies in $50 \mathrm{~mm}$ Tris (pH 7.9), $100 \mathrm{~mm} \mathrm{NaCl}, 10 \mathrm{~mm}$ EDTA, 0.5\% SDS, and 200 $\mu \mathrm{g}$ of proteinase $\mathrm{K}$ and incubating at $65^{\circ} \mathrm{C}$ for $1 \mathrm{hr}$. After two cycles of phenol/chloroform extractions, the DNA was ethanol precipitated and redissolved in TE $(10 \mathrm{mM}$ Tris at $\mathrm{pH} 8.0,1 \mathrm{mM}$ EDTA). DNA from 10 adults $(\sim 4 \mu \mathrm{g})$ was digested with the appropriate enzymes and then size fractionated on $0.8 \%$ agarose gels in TPE buffer $190 \mathrm{~mm}$ Tris-phosphate, $2 \mathrm{~mm}$ EDTA at $\mathrm{pH}$ 8.0). DNA was transferred to Hybond $\mathrm{N}+$ membranes (Amersham) in $0.4 \mathrm{~N} \mathrm{NaOH}$ and hybridized according to the supplier's instructions. This method was used to initially determine the insertion sites of the P elements and later map the changes in all of the imprecise excisions and some revertants.

RNA was recovered from hand-dissected ovaries or whole individuals by homogenizing in $3 \mathrm{M} \mathrm{LiCl}, 6 \mathrm{M}$ urea, $0.2 \%$ SDS, and overnight precipitation of RNA on ice. After centrifugation, the RNA was redissolved in TE $(0.1 \%$ SDS $)$ and extracted with phenol/chloroform $(1: 1)$, and chloroform. Poly(A) ${ }^{+}$RNA was isolated on oligo(dT)-cellulose columns, size fractionated on formaldehyde-agarose gels (Sambrook et al. 1989), and transferred to Hybond $\mathrm{N}+$ in $50 \mathrm{~mm} \mathrm{NaOH}$. Both Northern and Southern blots were hybridized with double stranded DNA labelled by random priming.

\section{Staining embryos and ovaries}

Ovaries from well-fed females were hand dissected in buffered ringers and fixed for $10 \mathrm{~min}$ in a mixture of $6 \%$ formaldehyde, $16 \mathrm{mM} \mathrm{KPO}_{4}$ (pH 6.8), $75 \mathrm{~mm} \mathrm{KCl}, 25 \mathrm{~mm} \mathrm{NaCl}, 3 \mathrm{~mm} \mathrm{MgCl}$, and an equal volume of heptane. The tissue was rinsed twice in PBS and stained for $10 \mathrm{~min}$ in a $1 \mu \mathrm{g} / \mathrm{ml}$ solution of DAPI in PBS. The ovaries were then washed twice in PBS and viewed under epifluorescence. For $\beta$-galactosidase staining, ovaries were fixed as described for DAPI and then stained in $10 \mathrm{~mm}$ $\mathrm{KPO}_{4}$ (pH 7.2), $150 \mathrm{~mm} \mathrm{NaCl}, 1 \mathrm{~mm} \mathrm{MgCl}{ }_{2}, 3.1 \mathrm{~mm} \mathrm{~K} 3 \mathrm{Fe}(\mathrm{CN})_{6}$, $3.1 \mathrm{mM} \mathrm{K}_{4} \mathrm{Fe}(\mathrm{CN})_{6}$, and $0.2 \% \mathrm{X}$-gal for $3-12 \mathrm{hr}$ at $37^{\circ}$. All X-gal stained tissue was photographed with Nomarski optics using a red filter to enhance contrast. Cuticles were prepared as described in Wieschaus and Nüsslein-Volhard (1986). All micrographs were made on a Zeiss Axioplan photomicroscope.

\section{Acknowledgments}

I thank Trudi Schüpbach, Allan Spradling, and Celeste Berg for supplying fly stocks and Sue Haynes for mapping $H r b 87 F$ and $B 54$ to the cosmid walk. Valuable comments on an early version of the paper were provided by Trudi Schüpbach, Allan Spradling, Mitzi Kuroda, and Karen Artzt. I especially thank Gideon Dreyfuss and Erika Matunis for valuable discussions about hnRNP proteins and sharing information about hrp 40 before publication. I am also grateful to Mitzi Kuroda for providing laboratory space for the final experiments. This work was supported by a Junior Faculty Research Award (JFRA-239) from the American 
Cancer Society and a Basil O'Connor Starter Award (5-683) from the March of Dimes Birth Defects Foundation.

The publication costs of this article were defrayed in part by payment of page charges. This article must therefore be hereby marked "advertisement" in accordance with 18 USC section 1734 solely to indicate this fact.

\section{References}

Anderson, K.V. 1989. Drosophila: The maternal contribution. In Genes and embryos (ed. D.M. Glover and B.D. Hames), pp. 1-37. IRL Press, Oxford, UK.

Ashburner, M., P. Thompson, J. Roote, P.F. Lasko, Y. Grau, M. El Messal, S. Roth, and P. Simpson. 1990. The genetics of a small autosomal region of Drosophila melanogaster containing the structural gene for alcohol dehydrogenase. VII. Characterization of the region around the snail and cactus loci. Genetics 126: 679-694.

Baker, B.S. 1989. Sex in flies: The splice of life. Nature 340: 521-524.

Bandziulis, R.J., M.S. Sqanson, and G. Dreyfuss. 1989. RNAbinding proteins as developmental regulators. Genes \& Dev. 3: $431-437$.

Bell, L.R., E.M. Maine, P. Schedl, and T.W. Cline. 1988. Sexlethal, a Drosophila sex determination switch gene, exhibits sex-specific RNA splicing and sequence similarity to RNA binding proteins. Cell 55: 1037-1046.

Cavener, D.R. 1987. Comparison of the consensus sequence flanking translation start sites in Drosophila and vertebrates. Nucleic Acids Res. 15: 1353-1361.

Champlin, D.T., M. Frasch, H. Saumweber, and J.T. Lis. 1991. Characterization of a Drosophila protein associated with boundaries of transcriptionally active chromatin. Genes \& Dev. 5: 1611-1621.

Chasan, R., Y. Jin, and K.V. Anderson. 1992. Activation of the easter zymogen is regulated by five other genes to define dorsal-ventral polarity in the Drosophila embryo. Development 115: 607-616.

Cheung, H.-K., T. Serano, and R.S. Cohen. 1992. Evidence for a highly selective RNA transport system and its role in establishing the dorsoventral axis of the Drosophila egg. Development 114: 653-661.

Clifford, R.T. and T. Schüpbach. 1989. Coordinately and differentially mutable activities of torpedo, the Drosophila melanogaster homolog of the vertebrate EGF receptor gene. $\mathrm{Ge}$ netics 123: 771-787.

Cobianchi, F., D.N. SenGupta, B.Z. Zmudzka, and S.H. Wilson. 1986. Structure of rodent helix-destabilizing protein revealed by cDNA cloning. J. Biol. Chem. 261: 3536-3543.

Cooley, L., R. Kelley, and A. Spradling. 1988. Insertional mutagenesis of the Drosophila genome with single $\mathrm{P}$ elements. Science 239: 1121-1128.

Cooley, L., C. Berg, R. Kelley, D. McKearin, and A. Spradling, 1989. Identifying and cloning Drosophila genes by single $P$ element insertional mutagenesis. In Progress in nucleic acid research and molecular biology (ed. W.E. Cohn and K. Moldave), vol. 36, pp. 99-110. Academic Press, San Diego, CA.

Cooley, L., E. Verheyen, and K. Ayers. 1992. chickadee encodes a profllin required for intercellular cytoplasm transport during Drosophila oogenesis. Cell 69: 173-184.

Dalton, D., R. Chadwick, and W. McGinnis. 1989. Expression and embryonic function of empty spiracles: A Drosophila homeo box gene with two patterning functions on the anterior-posterior axis of the embryo. Genes \& Dev. 3: 19401956.
Doyle, H.J., R. Kraut, and M. Levine. 1989. Spatial regulation of zerknült: A dorsal-ventral patterning gene in Drosophila. Genes \& Dev. 3: 1518-1533.

Ephrussi, A., L.K. Dickinson, and R. Lehman. 1991. oskar organizes the germ plasm and directs localization of the posterior determinant nanos. Cell 66: 37-50.

Frohnhöfer, G. H. and C. Nüsslein-Volhard. 1987. Maternal genes required for the anterior localization of the bicoid activity in the embryo of Drosophila. Genes \& Dev. 1: 880890.

Ghisolfi, L., G. Joseph, F. Amalric, and M. Erard. 1992. The glycine-rich domain of nucleolin has an unusual supersecondary structure responsible for its RNA-helix-destabilizing properties. J. Biol. Chem. 267: 2955-2959.

Govind, S. and R. Steward. 1991. Dorsoventral pattern formation in Drosophila: Signal transduction and nuclear targeting. Trends Gen. 7: 119-125.

Hashimoto, C., K.L. Hudson, and K.V. Anderson. 1988. The Toll gene of Drosophila, required for dorsal-ventral embryonic polarity, appears to encode a transmembrane protein. Cell 52: 269-279.

Hashimoto, C., S. Gerttula, and K.V. Anderson. 1991. Plasma membrane localization of the Toll protein in the syncytial Drosophila embryo: Importance of transmembrane signal for dorso-ventral pattern formation. Development 111: 10211028.

Haynes, S.R., D. Johnson, G. Raychaudhuri, and A.L. Beyer. 1991. The Drosophila Hrb87F gene encodes a new member of the A and B hnRNP protein group. Nucleic Acids Res. 19: $25-31$.

Kiledjian, M. and G. Dreyfuss. 1992. Primary structure and binding activity of the hnRNP $U$ protein: Binding RNA through RGG box. EMBO I. 11: 2655-2664.

Kim-Ha, J., J.L. Smith, and P.M. Macdonald. 1991. oskar mRNA localization to the posterior pole of Drosophila oocyte. Cell 66: 23-36.

King, R.C. and R.G. Burnett. 1959. An autoradiographic study of uptake of tritiated glycine, thymidine, and uradine by fruit fly ovaries. Science 129: 1674-1675.

Langer-Safer, P.R., M. Levine, and D.C. Ward. 1982. Immunological method for mapping genes on Drosophila polytene chromosomes. Proc. Natl. Acad. Sci. 79: 4381-4385.

Laski, F.A., D.C. Rio, and G.M. Rubin. 1986. Tissue specificity of Drosophila $P$ element transposition is regulated at the level of mRNA splicing. Cell 44: 7-19.

Levine, M. and K.W. Harding. 1989. Drosophila: The zygotic contribution. In Genes and embryos (ed. D.M. Glover and B.D. Hames), pp. 39-94. IRL Press, Oxford, UK.

Lindsley, D.L. and G. Zimm. 1992. The genome of Drosophila melanogaster. Academic Press, San Deigo, CA.

Macdonald, P.M., S. K-S. Luk, and M. Kilpatrick. 1991. Protein encoded by the exuperantia gene is concentrated at sites of bicoid mRNA accumulation in Drosophila nurse cells but not in oocytes or embryos. Genes \& Dev. 5: 2455-2466.

Mahowald, A.P. and M. Tiefert. 1970. Fine structural changes in the Drosophila oocyte nucleus during a short period of RNA synthesis. Wilhelm Roux's Arch. 165: 8-25.

Mahowald, A.P. and M.P. Kambysellis. 1980. Oogenesis. In The genetics and biology of Drosophila (ed. M. Ashburner and T. Wright), vol. 2d, pp. 141-225. Academic Press, London/New York.

Manseau, L.J. and T. Schüpbach. 1989. cappuccino and spire: Two unique maternal-effect loci required for both anteroposterior and dorsoventral patterns of the Drosophila embryo. Genes \& Dev. 3: 1437-1452.

Matunis, E.L. 1992. "Characterization of the major heteroge- 
neous nuclear ribonuclear proteins of Drosophila melanogaster." Ph.D. dissertation, Northwestern University, Evanston, IL.

Matunis, M.J., E.L. Matunis, and G. Dreyfuss. 1992a. Isolation of hnRNA complexes from Drosophila melanogaster. J. Cell Biol. 116: 245-255.

Matunis, E.L., M.J. Matunis, and G. Dreyfuss. 1992b. Characterization of the major hnRNP proteins from Drosophila melanogaster. J. Cell Biol. 116: 257-269.

Mayeda, A. and A.R. Krainer. 1992. Regulation of alternative pre-mRNA splicing by hnRNP A1 and splicing factor SF2. Cell 68: 365-375.

Montell, D.J., H. Keshishian, and A.C. Spradling. 1991. Laser ablation studies of the role of the Drosophila oocyte nucleus in pattern formation. Science 254: 290-293.

Mowry, K.L. and D.A. Melton. 1992. Vegetal messenger RNA localization directed by a 340-nt RNA sequence element in Xenopus oocytes. Science 255: 991-994.

Nagai, K., C. Oubridge, T.H. Jessen, J. Li, and P.R. Evans. 1990. Crystal structure of the RNA-binding domain of the Ul small nuclear ribonucleoprotein A. Nature 348: 515-520.

Nagoshi, R.N., M. McKeown, K.C. Burtis, J.M. Belote, and B.S. Baker. 1988. The control of alternative splicing at genes regulating sexual differentiation in Drosophila melanogaster. Cell 53: 229-236.

Price, J.V., R.J. Clifford, and T. Schüpbach. 1989. The maternal ventralizing locus torpedo is allelic to faint little ball, an embryonic lethal, and encodes the Drosophila EGF receptor homolog. Cell 56: 1085-1092.

Prost, E., F. Deryckere, C. Roos, M. Haenlin, V. Pantersco, and E. Mohier. 1988. Role of the oocyte nucleus in determination of the dorsoventral polarity of Drosophila as revealed by molecular analysis of the K10 gene. Genes \& Dev. 2: 891-900.

Ray, R.P., K. Arora, C. Nüsslein-Volhard, and W.M. Gelbart. 1991. The control of cell fate along the dorsal-ventral axis of the Drosophila embryo. Development 113: 35-54.

Robertson, A.M., C.R. Preston, R.W. Phillis, D. Johnson-Schlitz, W.K. Benz, and W.R. Engels. 1988. A stable genomic source of P element transposase in Drosophila melanogaster. $\mathrm{Ge}$ netics 118: 461-470.

Robinow, S., A.R. Campos, K.-M. Yao, and K. White. 1988. The elav gene product of Drosophila, required in neurons, has three RNP consensus motifs. Science 242: 1570-1572.

Roth, S., D. Stein, and C. Nüsslein-Volhard. 1989. A gradient of nuclear localization of the dorsal protein determines dorsoventral pattern in the Drosophila embryo. Cell 59: 11891202.

Rushlow, C.A., K. Han, J.L. Manley, and M. Levine. 1989. The graded distribution of the dorsal morphogen is initiated by selective nuclear transport in Drosophila. Cell 59: 11651177.

St. Johnston, D., W. Driever, T. Berleth, S. Richstein, and C. Nüsslein-Volhard. 1989. Multiple steps in the localization of bicoid RNA to the anterior pole of the Drosophila oocyte. Development (Suppl.) 107: 13-19.

St. Johnston, D., D. Beuchle, and C. Nüsslein-Volhard. 1991. staufen, a gene required to localize maternal RNAs in the Drosophila egg. Cell 66: 51-64.

Sambrook, I., E.F. Fritsch, and T. Maniatis. 1989. Molecular cloning: A laboratory manual, 2nd ed. Cold Spring Harbor Laboratory Press, Cold Spring Harbor, New York.

Schejter, E.D. and B.-Z. Shilo. 1989. The Drosophila EGF receptor homolog (DER) gene is allelic to faint little ball, a locus essential for embryonic development. Cell 56: 1093-1104.

Schüpbach, T. 1987. Germ line and soma cooperate during oogenesis to establish the dorsoventral pattern of egg shell and embryo in Drosophila melanogaster. Cell 49: 699-707.

Schüpbach, T. and E. Wieschaus. 1991. Female sterile mutations on the second chromosome of Drosophila melanogaster. II. Mutations blocking oogenesis or altering egg morphology. Genetics 129: 1119-1136.

Stein, D. and C. Nüsslein-Volhard. 1992. Multiple extracellular activities in Drosophila egg perivitelline fluid are required for establishment of embryonic dorsal-ventral polarity. Cell 68: $1-20$.

Stein, D., S. Roth, E. Vogelsang, and C. Nüsslein-Volhard. 1991. The polarity of the dorsoventral axis in the Drosophila embryo is defined by an extracellular signal. Cell 65: 725-736.

Steller, H. and V. Pirrotta. 1985. A transposable P vector that confers selectable G418 resistance to Drosophila larvae. EMBO /. 4: 167-171.

Stephenson, E.C., Y. Chao, and J.D. Fackenthal. 1988. Molecular analysis of the swallow gene of Drosophila melanogaster. Genes \& Dev. 2: 1655-1665.

Steward, R. 1987. dorsal, an embryonic polarity gene in Drosophila, is homologous to the vertebrate proto-oncogene, c-rel. Science 238: 692-694.

- 1989. Relocalization of the dorsal protein from the cytoplasm to the nucleus correlates with its function. Cell 59: 1179-1188.

Theurkauf, W.E., S. Smiley, M.L. Wong, and B.M. Alberts. 1992. Reorganization of the cytoskeleton during Drosophila oogenesis: Implications for axis specification and intercellular transport. Development 115: 923-936.

Wieschaus, E. 1980. A combined genetic and mosaic approach to the study of oogenesis in Drosophila. In Development and neurobiology of Drosophila (ed. O. Siddiqi, P. Babu, L.M. Hall, and J.C. Hall), pp. 89-94. Plenum Press, New York.

Wieschaus, E. and C. Nüsslein-Volhard. 1986. Looking at embryos. in Drosophila: A practical approach (ed. D.B. Roberts|, pp. 199-227. IRL press, Oxford, UK.

Wieschaus, E., J.L. Marsh, and W. Gehring. 1978. fs(1)K10, a germline-dependent female sterile mutation causing abnormal chorion morphology in Drosophila melanogaster. Wilhem Roux's Arch. Dev. Biol. 184: 75-82. 


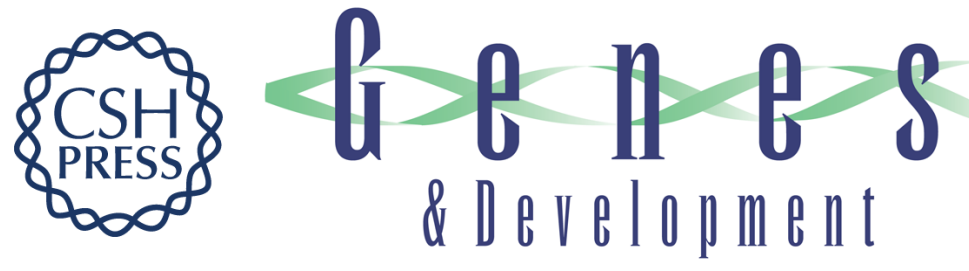

\section{Initial organization of the Drosophila dorsoventral axis depends on an RNA-binding protein encoded by the squid gene.}

R L Kelley

Genes Dev. 1993, 7:

Access the most recent version at doi:10.1101/gad.7.6.948

References This article cites 56 articles, 30 of which can be accessed free at:

http://genesdev.cshlp.org/content/7/6/948.full.html\#ref-list-1

License

Email Alerting

Service

Receive free email alerts when new articles cite this article - sign up in the box at the top right corner of the article or click here.

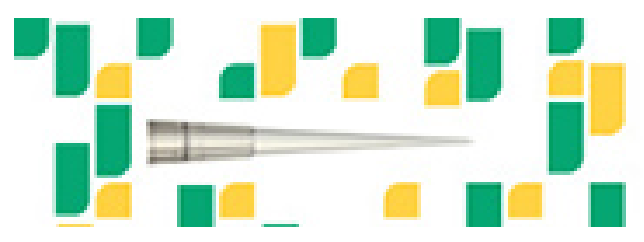

Focused on your science. 